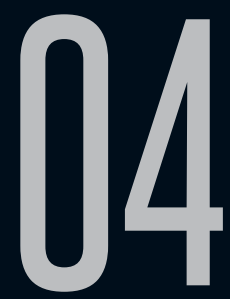

\title{
CONTOS DO LOOP E A RESISTÊNCIA À DISTOPIA CONTEMPORÂNEA
}

Pedro Sasse

Julliana Bomfim

Recebido em 21 nov 2020. Pedro Sasse

Aprovado em 18 abr 2021. Doutor em Estudos de Literatura (UFF, 2019).

Pesquisador nos seguintes grupos de pesquisa (CNPQ): "Estudos do Gótico", "Interferências: Literatura e Ciência" e "Escritos Suspeitos".

https://orcid.org/0000-0001-7441-7122

Julliana Bomfim

Mestre em Ciência, Tecnologia e Educação (2017) pelo Programa de Pós-Graduação em Ciência, Tecnologia e Educação (PPCTE) do Centro Federal de Educação Tecnológica Celso Suckow da Fonseca (CEFET/RJ). https://orcid.org/0000-0003-0325-4279

Resumo: Produções recentes como as séries Black Mirror (Netflix), Eletric Dreams (Amazon Prime) e Years and Years (BBC One) vem alimentando o imaginário contemporâneo com visões distópicas da sociedade, nas quais ganham relevo discussões sobre a alienação, reificação, controle e vigilância potencializados pela tecnologia. Na contramão dessa forte tendência da ficção científica contemporânea, surge Contos do Loop, taxada pela mídia de antiBlack Mirror por sua abordagem humanizada, sensível e, em última instância, otimista da relação 
entre o homem e a tecnologia. Outro aspecto importante que opõe essa série de seus pares é a escolha da época em que se passa a narrativa: não no futuro, mas no passado, sendo, assim, um representante contemporâneo da vertente da ficção científica conhecida como retrofuturismo. Através de uma análise tanto da série quanto do livro que the serve de inspiração, Ur Varselklotet, de Simon Stålenhag, pretendemos mostrar como o retrofuturismo surge do mesmo contexto de crise que alimenta o imaginário distópico, projetando num passado nostálgico - mais crítico - visões de futuro que não mais encontram paridade com as expectativas contemporâneas.

Palavras-chave: Distopia. Retrofuturismo. Ficção científica. Nostalgia. Esperança.

Abstract: Recent series productions like Black Mirror (Netflix), Eletric Dreams (Amazon Prime) and Years and Years (BBC One) have been nurturing our contemporary collective imagination with distopic visions of society, in which discussions on alienation, reification, control and vigilance have been gaining attention due to its increasing technological optimization. Tales from the Loop premieres opposing contemporary science fiction's mainstream tendency. The media tagged it as an anti-Black Mirror narrative because of its humane, sensitive and even optimistic approach on the relationship between mankind and technology. The choice to set the narrative in the past is another important aspect that distinguishes this series from its futuristic counterparts, which makes it a contemporary representative of $\mathrm{sci}$ - $\mathrm{fi}$ branch retrofuturism. Through an analysis of the series and the book that inspired it - Ur Varselklotet, by Simon Stålenhag - we intend to show how retrofuturism comes from the same crisis context that can, at the same time, feed this distopic imagination and project, in a nostalgic 
past, visions of future that no longer find parity in contemporary expectations.

Keywords: Dystopia. Retrofuturism. Science fiction. Nostalgia. Hope.

Em meados de 2020, uma suposta propaganda da sexta temporada de Black Mirror viraliza: em uma parada de ônibus, um espelho escuro e manchado reflete os transeuntes; acima dele vemos os dizeres "6th Season. Live now, everywhere". Se a própria concepção da série já envolvia a ideia de uma mímesis sombria da realidade, a imagem simbolizou sua concretização no imaginário. Longe de ser uma real propaganda da série, ainda sem previsão para uma nova temporada, a imagem era parte do exercício de um curso de criatividade na Espanha e seu alcance mundial, a partir de uma única foto modificada digitalmente, é a prova da ampla identificação do público contemporâneo com esse reflexo.

Um pouco antes, já víamos se popularizar na internet frases como "Isso é muito Black Mirror", que chegou a nomear, no Brasil, um dossiê da revista Superinteressante sobre a proximidade do mundo apresentado na série e o nosso. Os dizeres são utilizados quando se testemunha determinado evento real que se reveste de ares distópicos, borrando as fronteiras entre a realidade e a sátira sombria. Reconhecimento facial, algoritmos manipuladores de desejos, inteligências artificias, extremismo político magnificado pelas redes sociais, linchamentos virtuais, policiamento constante e extremado do politicamente correto, não faltam temas sobre os quais poderíamos dizer "Isso é muito Black Mirror".

Em 2018, o escritor Daniel Olivas, escreveu para o The New York Time uma coluna intitulada "The Dystopia is here", em que 
confessa certo fracasso em sua tentativa de construir uma distopia como advertência ao presente, função que normalmente se atribui ao gênero:

Eu queria que minha história servisse como um conto de advertência sobre o que nosso país poderia se tornar caso as políticas imigratórias do Sr. Trump fossem totalmente concretizadas. Mas agora é a nossa realidade: filhos e filhas estão sendo arrancados dos braços de seus pais - em alguns casos literalmente - e centros de detenção estão ficando cheios de crianças apavoradas. Em comunidades imigrantes, o medo é palpável, com pais se perguntando se eles deveriam arriscar levar seus filhos à escola ou ir trabalhar ou denunciar um crime, temendo se tornarem vulneráveis a uma batida dos agentes da imigração. (OLIVAS, 2018, tradução nossa)

Black Mirror, no entanto, não foi o único a inspirar esse tipo de paralelo no público. Em 2017 a emissora Hulu produziu uma série baseada no romance homônimo de Margaret Atwood, $O$ Conto da Aia, mostrando que, mesmo três décadas depois de sua publicação, a ameaça de ascensão de poderes extremistas religiosos e o controle do corpo feminino ainda - ou novamente - são temas importantes para pensar o presente. No mesmo ano, os contos de Phillip K. Dick também ganham adaptação no distópico Eletric Dreams, associado não raramente a Black Mirror em sua proposta. Vale ainda lembrar como, em 2019, outra série foi anunciada como um derivado do fenômeno Black Mirror, a britânica Years and Years, da BBC.

A transformação de Black Mirror em uma espécie de categoria midiática, de eixo comparativo tanto para a ficção quanto para 
a realidade, é um forte sintoma de que, por um lado, a visão que veicula - sobretudo a visão de ciência -, hoje, se tornou não apenas uma possibilidade, mas parte consistente de nosso zeitgeist. Se o século XIX foi marcado por uma predominante visão idealizada da ciência - ainda que textos prototípicos da ficção científica e do gótico problematizassem tal visão - e o século XX tenha inaugurado uma virada distópica nessa visão sobretudo após a segunda guerra mundial -, o século XXI parece sinalizar a concretização dos pesadelos das gerações passadas: instrumentalizado pelos piores lados do capitalismo, alimentando a reascensão do fascismo e acelerando a degradação ambiental a níveis irreversíveis. Dessa forma, é difícil enxergar nessa ciência um espelho que não seja sombrio.

Nesse sentido, é curioso o recente fenômeno apresentado pela mídia - mantendo sua tendência comparativa - como o "antiBlack Mirror": a série Contos do Loop, produzida e disponibilizada pela Amazon Prime, baseada nas intrigantes pinturas de ficção científica do artista sueco Simon Stålenhag. Situada em um passado retrofuturista, a série explora delicados temas da natureza humana através da óticas heterogêneas de seus diversos personagens, que habitam a cidade ficcional de Mercer no interior de uma Ohio futurista dos anos oitenta.

O título antagônico à série distópica da Netflix não se deve, no entanto, à construção de uma utopia tecnológica. Contos do Loop mostra a ciência como passível de falhas e acidentes, vulnerável à eventual hybris dos seus cientistas e suas consequências. Muitas das histórias inclusive, com uma mudança de abordagem, poderiam figurar entre as angustiantes histórias de Black Mirror, 
com episódios sobre aprisionamento de corpos em máquinas ou a ameaça representada por um robô nas mãos erradas. $\mathrm{O}$ que a opõe, assim, à sua contraparte reside menos na existência de dada tecnologia do que em sua relação com o elemento humano da série.

Enquanto Black Mirror e seus similares trazem como elementos centrais de suas reflexões o poder reificador da tecnologia e sua capacidade de alienar e manipular as massas em uma sociedade carente de valores como empatia, ética e sensibilidade, Contos do Loop aposta que a despeito dos terrores que podem acompanhar o surgimento das novas tecnologias, o lado humano pode prevalecer. Ódio, desespero e desilusão abrem, dessa forma, espaço para uma recuperação de valores como amadurecimento, compaixão, luto, amizade e amor.

Se, como Olivas concluiu, de fato, a distopia já está entre nós, e o gênero perdeu muito de seu poder admonitório para se tornar um reforço desiludido da decadência da sociedade contemporânea, Contos do Loop representa uma tentativa complexa de resgate de uma visão de ciência e sociedade muito avessa às tendências pós-modernas. Buscamos, assim, para analisar a peculiar posição dessa série da Amazon Prime ${ }^{1}$, abordá-la através de uma ótica multidisciplinar: por um lado, entendendo a obra dentro da tradição do retrofuturismo e analisando como esse impulso nostálgico se associa à crise que alimenta o imaginário distópico, funcionando como resistência ao pessimismo absoluto; por outro, seguindo a perspectiva da História e Filosofia da Ciência, refletindo sobre as condições históricas de surgimento do gênero e como

1 Vale ressaltar a ironia de uma série que representa valores tão distintos daqueles simbolizados pela empresa que a produziu, cujo dono se aproxima hoje de ser o primeiro trilionário do mundo até o final da década. 
a visão da ciência pela sociedade tem um grande peso tanto no fortalecimento dessas visões negativas de futuro - ganhando força com o cyberpunk nos anos 70-80 - quanto na recuperação idealizada de uma perspectiva anterior - plasmada na primeira onda do retrofuturismo na mesma época.

Em um momento em que a ascensão de regimes de inclinação fascista atacam a comunidade científica, mas, ao mesmo tempo, instrumentalizam a tecnologia para a vigilância, controle e exploração da sociedade, Contos do Loop surge como um pequeno, mas importante impulso de valorização de uma ciência para além do puro utilitarismo, em que o fator humano assume um papel central e, assim, tenta recuperar um ideal de futuro que nossas previsões mais céticas são incapazes de vislumbrar a partir da contemporaneidade.

\section{DE MÄLARÖARNA A MERCER}

Em 2014, o artista visual sueco Simon Stålenhag produz uma série de pinturas que reúne sob o título de Ur Varselklotet, traduzido ao inglês como Tales from the Loop, publicado no ano seguinte em um livro narrativo de mesmo nome. A obra retrata através de pinturas e textos breves, uma história alternativa em que a Suécia abrigou o maior acelerador de partículas do mundo em uma instalação governamental de pesquisa experimental - o Loop - da qual vemos os ecos nas construções ultratecnológicas que se integram às bucólicas paisagens do interior escandinavo.

No entanto, longe de retratar grandes aventuras ou mistérios, ou de aprofundar as reflexões técnico-filosóficas que poderiam surgir dos experimentos de física de altas energias, o mundo 
apresentado por Stålenhag surpreende pelo curioso recorte escolhido. Primeiro, a opção de situar sua obra no passado - Ur Varselklotet se passa nos anos 90 -, fato não só mencionado nos textos que complementam os quadros, como capturado através de indícios visuais como os carros e roupas da época. Além disso, opta por uma perspectiva que, na verdade, evita o aprofundamento no mundo tecnológico, priorizando a ótica humana e não especializada, em que os cidadãos da pequena cidade de Mälaröarna, local que abriga as instalações do Loop, aparecem em primeiro plano, enquanto a tecnologia surge ora como mais um elemento integrado às paisagens naturais geralmente através do signo da ruína - ora delineada no horizonte distante, além das preocupações mundanas.

Figura 1. Crianças e torres de refrigeração ao fundo

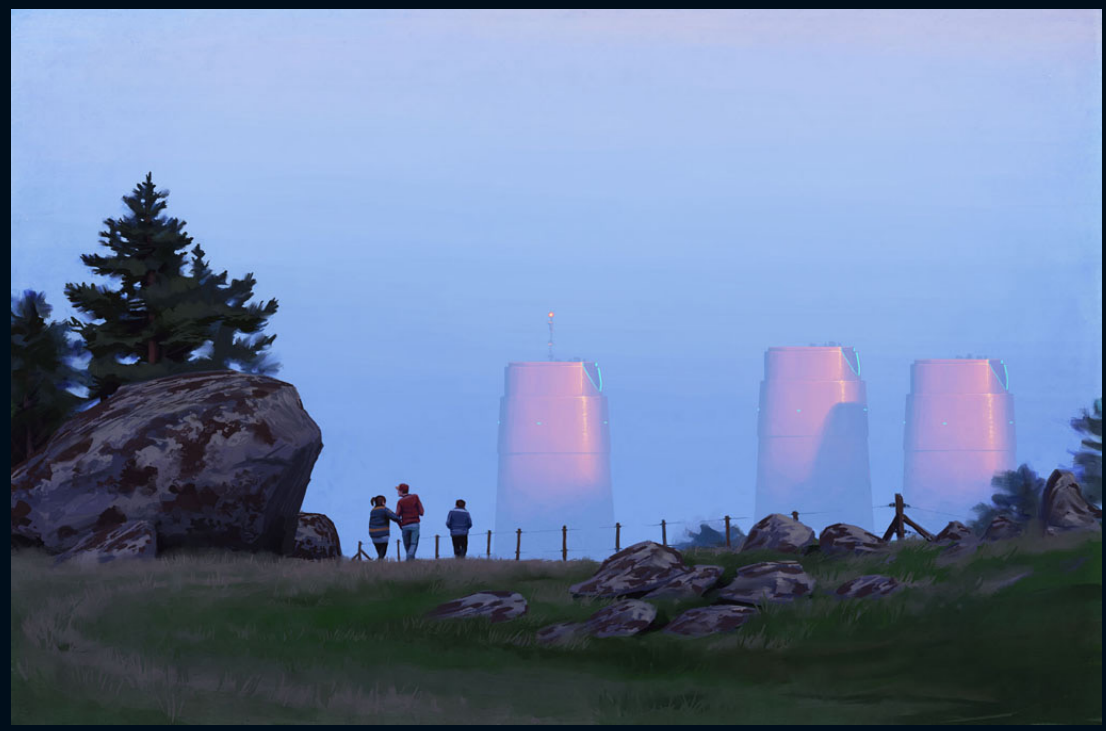

Fonte: Simon Stålenhag, 2014. Imagem sem título de Ur varselklotet (Contos do Loop). Disponível em: https://www.simonstalenhag.se/tftl.html. Acesso em: 20 set. 2020. 
Ainda que vejamos diferentes retratos do cotidiano de Mälaröarna, há uma clara inclinação à ótica infantil, marcada na frequente representação de crianças em primeiro plano, geralmente em atitudes descontraídas, brincando entre os resquícios do maquinário enferrujado ou olhando com curiosidade ingênua os resultados peculiares das pesquisas experimentais do Loop. Essa ótica, misturada ao recorte temporal situado no passado cria, em Ur Varselklotet, um efeito nostálgico de retorno a uma infância idealizada, em que a ciência é uma força desconhecida e quase mágica, isolada das problemáticas relações políticas que a acompanham. Tal inclinação é expressa pelo próprio autor em sua admiração pelo olhar infantil sobre o mundo, em entrevista ao jornal The Guardian:

\begin{abstract}
"Eu não me sinto um adulto", ele diz depois. "Eu gosto das crianças porque eu não acho que elas conheçam segredos. Elas estão suficientemente alheias. É importante que adultos existam, para que crianças possam continuar alheias, mas eu sempre me senti mais simpatético pelos jovens porque eles um olhar fresco. (CAIN, 2020, tradução nossa)
\end{abstract}

Ainda que as imagens façam o trabalho central nessa obra, Stålenhag intercala os intrigantes quadros com textos breves nos quais tece o contexto do mundo que constrói:

O Loop estava nas profundezas subterrâneas. Era um enorme acelerador de partículas e centro de pesquisa em física experimental [...]. A presença era sentida por todas as partes de Mälaröarna. Nossos parentes trabalhavam lá. Veículos de serviço da Riksenergi patrulhavam a terra e os céus. Estranhas máquinas vagavam nas florestas, clareiras e prados. Quaisquer que fossem as forças 
que reinavam naquelas profundezas, elas enviavam suas vibrações pela rocha-mãe, pelos tijolos sílicocalcários e pelas fachadas da Eternit e por nossas salas de estar.

A paisagem estava cheia de máquinas e sucata relacionadas de uma maneira ou outra com o centro de pesquisa. Sempre presente no horizonte, as torres de refrigeração do reator de Bona, com suas luzes de visibilidade verdes. Se você colocasse a orelha no chão, poderia ouvir o coração pulsante do Loop: o ronronar do Gravitron, a peça central da engenharia mágica que era o foco dos experimentos do Loop. As instalações eram as maiores do seu tipo no mundo, e se dizia que suas forças poderiam dobrar o espaço-tempo. (STÅLENHAG, 2015, p. 3, tradução nossa)

É importante destacar a voz narrativa que perpassa a maioria dos textos: uma voz marcada pelo ato de rememoração, com tom algo nostálgico, alheio às especificidades mais técnicas do Loop e seus experimentos. É uma voz que naturaliza a tecnologia, dandoIhe um "coração pulsante" e a fazendo "ronronar". Ainda que, eventualmente, a narrativa seja intercalados com outros gêneros textuais, como propagandas e instruções de uso das máquinas, predominam nela os curtos relatos ou reflexões que apresentam o contato quase fantástico com um mundo ao mesmo tempo familiar, por sua integração orgânica à paisagem, e desconhecido, por suas capacidades além da compreensão daqueles que com ela interagem.

Essa voz narrativa acentua profundamente a importância da memória na obra, já que se trata de um cenário que, apesar de futurista, se situa no passado. Texto e imagem se suplementam na construção de uma visão nostálgica, carregada de sentimentos do universo infantil: leveza, liberdade, curiosidade, descoberta. 
A relação desse passado futurista se torna ainda mais complexa quando levamos em consideração a curiosa presença da ruína e da sucata como elementos chave nos quadros. Tais elementos se afastam de sentidos que são atribuídos a elas com mais frequência, como decadência, abandono e morte. Estando o Loop em pleno funcionamento, essa inserção se dá como um signo não de degeneração, mas de fundação de um passado mítico-tecnológico. Para o olhar infantil, sobretudo, a presença das máquinas e estruturas enferrujadas reforça a ideia de que sempre houve tais tecnologias ali. Cobertas de musgo, servindo de abrigos para animais ou se confundindo com a silhueta das árvores na floresta, essa tecnologia não é uma inovação invasiva, alterando drasticamente a vida dos moradores de Mälaröarna, mas parte indissociável de sua vida e de sua história.

É curiosíssimo notar, no entanto, a discrepância entre a produção de Stålenhag e uma recepção despreparada para lidar com uma visão não distópica de ciência, tendo em vista a popularidade de uma perspectiva pautada por um paradigma Black Mirror de uso da tecnologia. Não há praticamente nada nas pinturas do artista sueco que inspirem ameaça, desintegração social, controle, opressão, vigilância, medo ou supremacia. Stålenhag nos expõe um mundo em que a tecnologia aparece alienada no tempo - ruínas, sucatas -, no espaço - as torres e máquinas trabalhando distantes, quase no horizonte - ou integrada de forma rotineira no dia a dia de uma cidade do interior: tratores antigravitacionais solitários ao sol fazendo a colheita; ou robôs que se comportam como curiosos e inofensivos animais silvestres. Ainda assim, antes de escrever a parte textual do livro, 
quando havia apenas publicado as pinturas, percebia uma forte discrepância entre o mundo que havia imaginado ao produzi-las e aquele imagino pelos fãs a partir de seu trabalho:

Stålenhag escreveu seu mais famoso livro, Tales from the Loop, porque fãs estavam mandando histórias para ele baseadas em suas pinturas. Ele estava chocado. "Eu estava tipo 'Isso não serve. Vocês precisam saber exatamente como eu o concebi'. Eles estavam muito longe, muito distópicos, ele diz. "A diferença entre distopia e futurismo, para mim, é que, no meu mundo, há chocolate quente esperando por você em casa". (CAIN, 2020, tradução nossa)

Longe de pensar que a intenção de Stålenhag deveria pautar a leitura que se faz de sua obra, acreditamos que a discrepância entre essas visões reforça a dificuldade em se fugir de uma visão distópica da ciência mesmo diante de uma obra arquitetada para ser seu oposto. Ainda que o The Guardian dê voz ao autor para que declare seu afastamento do gênero, o próprio jornal não colabora para uma visão diferente: a obra do artista sueco já figurava em uma lista das dez melhores distopias publicada pelo jornal em sua coluna de cultura anos antes (LODGE, 2014); e a própria entrevista em que Stålenhag faz essa declaração é intitulada "Distopia com chocolate quente".

Antes de a fama de Ur Varselklotet alcançar os escritórios da Amazon, um projeto menor ajudou a consolidar sua popularidade: uma campanha de financiamento coletivo para a produção de um livro de RPG baseado na obra de Stålenhag. Recebendo mais de cinco mil apoios, a campanha foi um absoluto sucesso, e ajudou a sinalizar o desejo de aprofundamento do público no mundo do 
Loop. Nesse RPG, os jogadores assumiam o papel de adolescentes se unindo para desvendar mistérios sobre o centro de pesquisas, aventurando-se entre máquinas e estranhas criaturas. Tal enredo se alinha, talvez, menos com o mundo pintado pelo artista do que com outro importante exemplar da onda de nostalgia dos últimos anos: a série da Netflix Stranger Things, em que um grupo de préadolescentes - jogadores de RPG, diga-se de passagem - se unem para desvendar os misteriosos ataques que ocorrem em uma pequena cidade do anterior devido a experiências feitas em uma instalação de pesquisa científica experimental.

Tendo em vista o sucesso das campanhas anteriores relacionadas à obra, a Amazon Prime faz um grande investimento em Contos do Loop, que é lançado em 2020 contando com grande elenco, cenários primorosos e efeitos especiais impecáveis. Com oito episódios, a série tenta se aproximar do formato fragmentário de Ur Varselklotet ao optar por um enredo de histórias independentes situadas nos arredores das instalações do Loop. Ainda que o próprio livro mencione uma instalação do Loop americana, situada no cenário árido de Nevada, a produção decide traduzir o frio bucólico de Mälaröarna na cidade de Mercer, em Ohio, mantendo, assim, a correspondência das paisagens brancas vistas na ambientação escandinava.

Talvez para se afastar da abordagem popularizada pela Netflix em Stranger Things - situada em época semelhante -, a série decide variar as perspectivas da obra, mantendo, ainda alguns episódios centrados na visão infantil, mas transferindo, em outros, o foco não só para personagens adultos, mas trabalhadores do próprio Loop, em sua maioria. Com isso, parte do encanto alcançado pela 
voz narrativa de Ur Varselklotet dá lugar, muitas vezes, a reflexões e preocupações que, no livro, aparecem apenas quando filtradas pela ingenuidade infantil - e que geralmente a inclinam para uma visão menos idealizada daquele passado, apresentando problemas financeiros, morte, depressão, adultério e problemas conjugais.

Devido a esse mesmo olhar adulto, unido a uma natural necessidade de maior aprofundamento narrativo em uma adaptação que passa de fragmentos textuais a episódios de uma hora de duração, esvazia-se também, em parte, algo do encanto quase místico que inspiram as tecnologias do Loop na obra de Stålenhag. Já no primeiro episódio temos acesso a algo que jamais é mostrado no livro: o interior das instalações, incluído o próprio coração do Loop. Além disso, há, na série, uma maior exposição dos experimentos e suas consequências. Enquanto no livro, a maior parte dos fenômenos que envolvem tempo e espaço são apenas rumores que chegam aos ouvidos infantis do narrador, quase como mitos, na série vemos concretamente viagens temporais, trocas de corpo, mudanças de dimensão etc.

Um bom exemplo dessa mudança de foco pode ser visto entre o fragmento do livro "Jens e Håkan trocam de corpos" e o episódio da série "Transposição", cuja premissa é a mesma: dois garotos encontram uma máquina abandonada que os faz trocar de corpos.

No texto de Ur Varselklotet, a história, como a maioria das que tematizam os fenômenos envolvendo o espaço-tempo, é apresentada indiretamente, através de um relato dos próprios gêmeos Jens e Håkan. A escolha de Stålenhag de que a troca de corpos seja feita - e contada - por crianças gêmeas já aponta a 
importância da incerteza para a história: naturalmente duplos de si, a troca se esvazia de qualquer tipo de comprovação e, ainda que seja tomada como verdade, de qualquer consequência. Os corpos permanecem trocados, a mãe nunca percebe e tudo não passa de "uma história muito engraçada" (STÅLENHAG, 2015, p. 72).

Já no episódio de Contos do Loop, a história se afastará bastante da atmosfera descontraída do fragmento. Nele, Jacob, um introspectivo filho de pesquisadores do Loop, e seu carismático e extrovertido amigo Danny trocam de corpos. A princípio amedrontado com o fato, Jacob é convencido por Danny a manter a troca por uma noite. Jacob acaba, assim, aproveitandose do interesse feminino despertado pelo novo corpo atlético enquanto Danny, que vem de uma família pobre, experimenta os prazeres de uma vida mais confortável. A graça da troca termina quando Danny, no corpo de Jacob se aproxima da garota de quem o introvertido menino gostava. Jacob se sente traído pelo amigo e deseja voltar ao próprio corpo, mas Danny acaba decidindo não devolver o corpo para poder gozar permanentemente das facilidades de ser filho de um pesquisador do Loop e não de um mecânico, como era o seu caso. Jacob, desesperado, tenta fazer a troca sem o amigo por perto, e, assim, acaba acidentalmente trocando de corpo com uma das máquinas do local. A consciência fica presa ao corpo metálico e inexpressivo de um robô não humanoide, enquanto o corpo de Danny, sem consciência que o habite, entra em coma.

A história, uma das mais sombrias da série, parece compartilhar da mesma tendência antes mencionada de tentar aproximar as histórias de uma abordagem mais distópica, completamente 
destoante com a ideia do "chocolate quente esperando por você em casa" (CAIN, 2020. Tradução nossa) advogada por Stålenhag. Longe de ser apenas um causo engraçado de meninos conversando na escola, "Transposição" mostra uma história de traição e roubo de identidade que terminará em uma dupla tragédia: por um lado, Jacob ficará preso até sua morte em um corpo robótico primitivo, não tendo sequer capacidade de comunicação clara com o mundo exterior; e, por outro, a família de Danny, que sofrerá mantendo um filho em estado vegetativo enquanto o verdadeiro Danny usurpa o lugar de Jacob no mundo.

Apesar de uma mudança significativa em aspectos importantes para o projeto que Ur Varselklotet representa, a série consegue, em última instância, se aproximar do ponto crucial da criação de Stålenhag: o valor humano em primeiro plano. E talvez seja justamente esse ponto que fortaleça uma visão de Contos do Loop como uma espécie de anti-Black Mirror.

Na série da Netflix e em suas similares são recorrentes os temas relativos ao transumanismo - integração indissociável entre homem e máquina, orgânico e artificial - e a reificação do homem pela tecnologia, em que o jogo criador-criatura se inverte e a máquina controla seu usuário, algo não muito distante do que hoje o sistema de engajamento das redes sociais é capaz de fazer com uma grande parcela da população. Como exemplo desse transumanismo que representa a ansiedade - uma relação complexa de medo e desejo - de perda dos limites do humano podemos mencionar os muitos episódios centrados na tecnologia dos cookies em Black Mirror, uploads da mente humana para realidades virtuais ou aparelhos eletrônicos. É curioso perceber, 
aqui, uma característica que a separa do que foi a primeira onda dessa ansiedade transumana na literatura: o cyberpunk dos anos 80 - e sua sobrevivência até os dias de hoje. Nele, a integração homem-máquina ainda se dá de uma forma mais visível, palpável, através de implantes cibernéticos integrados ao corpo humano como vemos, por exemplo, no fundamental Neuromancer (1984), de William Gibson ${ }^{2}$ - e a recorrente presença dos androides. Em Black Mirror, essa integração acompanha as tendências atuais de maior foco nos processos digitais, em uma espacialidade outra, logo outra corporalidade também.

Já a reificação do homem pela tecnologia é vista de forma clara no segundo episódio da série, "quinze milhões de méritos", uma distopia em que todos precisam passar o dia pedalando no que parece ser um gerador de energia em troca de créditos para consumir mídias digitais. É também o tema de "Nosedive", em que a sociedade é pautada pelas redes sociais e a avaliação que os outros usuários fazem de cada um nela; ou ainda de "Smithreens", um episódio que dispensa as projeções de alta tecnologia e mergulha diretamente no problema dos sistemas de engajamento das redes sociais contemporâneas, reforçando, como visto na famosa montagem dos espanhóis, a ideia de paridade entre Black Mirror e a realidade.

Nessas histórias, perda de controle, de limites e de identidade são temas cruciais para marcar o caráter terrivelmente indissociável não tanto da tecnologia e do nosso corpo, como a visão dos anos 80 nos transmitia, mas enraizada profundamente na nossa

2 Por mais que Neuromancer apresente a Matrix como prenúncio desse espaço virtual que se consolidará posteriormente, não deixa de lado a representação do corpo ciborgue. 
sociedade, política e economia, na nossa vivência e na nossa própria consciência. É disso que se afasta o mundo de Stålenhag e sua adaptação, tentando recuperar, em um passado idealizado um mundo em que o ser humano ainda prevalece.

Isso não é feito, claro, através de um ludismo que renega a ciência e a tecnologia, mas de forma complexa, mostrando um mundo em que o valor humano persiste mesmo rodeado pelas máquinas. No livro, vemos como os aspectos futuristas são, paradoxalmente, formas de retornar ao passado, não através do controle espaço-temporal, apenas sugerido vagamente ao longo do livro ${ }^{3}$, mas através da memória. Dessa forma, se carregam de afetos, permitindo que o leitor experimente em vez de uma reificação do homem pela máquina, uma humanização da máquina pelo olhar subjetivo memorialista.

A série, que dispensa esse foco na memória, encontra outros caminhos para trazer o lado humano para o primeiro plano, sendo, talvez, o principal deles a importância dos laços afetivos. Vemos isso desde o primeiro episódio, "Loop", em que uma menina acidentalmente viaja para o futuro e acaba ficando amiga do filho que teria décadas mais tarde. No clímax da história, Loretta, a menina, encontra com sua versão mais velha e ambas conversam sobre a vida: a mãe da Loretta criança havia desaparecido pouco antes e a mais velha a consola e ajuda na compreensão do abandono, mostrando que, apesar de tudo, a pequena conseguiria formar uma boa família para aplacar o trauma da solidão. Por outro lado, ao ver a pequena Loretta na

3 Com exceção talvez da presença de alguns elementos pré-históricos integrados ao ambiente, como eventuais dinossauros. Tal parte destoa um pouco da abordagem mais sutil que impera no livro, tanto que a série opta por exclui-la da adaptação. 
condição que ela mesma experimentara em sua infância, a adulta, que andava negligenciando atenção aos filhos para dedicar-se ao trabalho, relembra da importância de sua própria família e se aproxima novamente deles.

Essa estrutura será a chave para todos os episódios que seguem "Loop", em que veremos como os diferentes cidadãos de Mercer são afetados pela presença das máquinas e ruínas apenas para delas conseguir extrair uma lição humana sobre laços: o amadurecimento emocional de uma adolescente em "Êxtase"; a importância da família na superação do luto em "Ecoesfera"; e mesmo a capacidade de se criar laços com as máquinas humanizadas, como em "Inimigos".

De fato, um dos episódios mais emotivos da série é justamente aquele em que o aspecto tecnológico tem menos impacto. Em "Ecoesfera", episódio centrado em Russ, personagem interpretado por Jonathan Price, o diretor do Loop e sogro da Loretta do primeiro episódio, está diagnosticado com uma doença terminal. Um golpe para toda a família, a notícia é especialmente mal recebida pelo jovem Cole, filho de Loretta, que era muito apegado ao avô. O episódio se desenvolve, assim, como uma jornada de processo do vindouro luto, enquanto Russ passa os momentos finais de sua vida ao lado do neto. A ecoesfera que dá nome ao episódio serve mais de metáfora que de concreta força motriz para o enredo, se diferenciando dos demais pela quase ausência do elemento caracterizador da ficção científica.

O episódio é livremente inspirada no fragmento "A ecoesfera" do livro, em que o narrador e dois amigos exploram as ruínas 
tecnológicas perdidas entre a floresta por pura brincadeira. No texto de Stålenhag, o único eco suscitado pela ecoesfera é aquele de seu próprio passado:

A ecoesfera jazia ali na pedreira. Um leve som zumbia dentro da esfera quando o vento ressoava entre as paredes de aço. Kalle e Olof imediatamente correram para dentro e começaram a gritar para testar o eco. Um par de gaviões nervosos circundavam do alto a esfera. Eu permaneci do lado de fora, lembrando daquele primeiro dia com meu avô. Relembrando agora, eu percebo que talvez essa seja minha primeira memória de sentir nostalgia. Estranho; um dia de verão e três meninos de nove anos, um dos quais parou no meio da brincadeira por causa de uma memória de infância. (STÅLENHAG, 2015, p. 20, tradução nossa)

O jogo criado pelo autor é um eco de memórias. O narrador rememora uma cena de infância e se surpreende, no meio dessa memória, que seu eu passado ali também fazia o mesmo ato, talvez por primeira vez, em um mise en abyme nostálgico. Vemos, nesse fragmento, a centralidade não só do papel da memória na obra, mas da nostalgia, que será responsável por emprestar a esse ato mnemônico os tons que colorem aquele passado de um idílio quase utópico.

A série, a fim de não fugir completamente do elemento tecnológico do qual o livro parece não se importar em distanciarse, dá a ecoesfera uma função mais palpável: aqueles que gritam nela conseguem, ao contar o número de ecos em seu interior, saber quantas décadas viverão ainda. Tal fato, no entanto, é não mais que um reforço às relações entre infância e velhice em que o episódio 
se centra, podendo, inclusive, ser interpretado como apenas uma anedota de Russ para maravilhar o seu neto.

Vemos, nesses pontos em que a série se permite quase uma completa desconexão de um elemento central para o gênero em que se insere, como se constrói um esforço de centralidade no aspecto humano que permeia todo o livro. Em última instância, se pode dizer que ambos são sobre transições: amadurecimentos, superações, envelhecimento, morte, mas também vida. E esse aspecto é bem captado, de forma bem diferente, tanto pelo fim da série quanto pelo fim do livro.

A série se encerra com o episódio "Casa”. Nele, Cole é agora o protagonista. A centralidade do personagem na série - um dos que aparece em mais episódios -, a idade, comportamento e paridade com certos fragmentos do livro nos permitem inferir que o menino é adaptado a partir do próprio protagonista de Ur Varselklotet, o eu do passado rememorado pelo narrador. O episódio reforça a solidão de Cole, cujo irmão - na verdade Danny no corpo de seu irmão - havia ido morar sozinho, o avô havia morrido e a mãe tivera que resolver problemas na capital, deixando o menino com um grande senso de desamparo. Cole, ao visitar o irmão, o descobre tomado pela culpa, e Danny Ihe revela a verdade. O menino encontra, então, seu verdadeiro irmãomáquina na floresta e juntos partem para tentar alcançar a mãe na cidade. No caminho encontram um robô hostil - talvez o único de Contos do Loop - e Cole é protegido por Jacob-robô, que acaba se avariando e, por fim, morre na floresta. O menino prossegue após fazer um memorial ao irmão e, sem sucesso em seu percurso, retorna a casa apenas para descobrir, ao encontrar uma Loretta 
envelhecida, que, por acidente, cruzara uma bolha temporal e ficara desaparecido por muitos anos. O episódio termina com uma rápida prolepse mostrando o resto da vida de Cole até a vida adulta, encerrando o episódio com as emblemáticas torres de resfriamento já presentes no livro.

O episódio tenta, dessa forma, capturar a tensão entre o mundo do narrador personagem adulto e o olhar infantil que pauta o episódio. É naquele passado que estão condensadas as suas memórias mais intensas, logo, um tempo marcado por maior duração afetiva. Após isso, sua vida adulta chega em um piscar de olhos e é apenas retornando a esse passado que pode sentir que realmente viveu.

Esse mesmo olhar confuso e angustiado de um menino diante de um mundo que já não é mais aquele de sua infância é justamente a força motriz de Ur Varselklotet. O livro, que não aposta nesse uso mais explícito das tecnologias mirabolantes, termina de forma mais sóbria, indicando apenas como, determinado dia, a infância passou, e, com ela, passou aquele mundo que o rodeava:

O Loop foi finalmente desativado no dia 5 de novembro de 1994. Nessa época, todos já tínhamos acne. A sociedade estava mudando; era óbvio para todos. Os carros amarelos do Loop desapareceram das estradas. As empresas estatais se tornaram privadas e mudaram de nome. Nós não sentimos essas mudanças quando elas ocorreram; estávamos muito ocupados com nossa pele oleosa e voz engrossando.

As brincadeiras foram sendo, peça a peça, substituídas por computadores. Pouco depois passávamos todo nosso tempo livre na frente de um computador. [...] 
Nós andávamos em grandes filas pelas noites de inverno, e você poderia ver pequenos pontos de luz acendendo e apagando na escuridão - cigarros fumados por adolescentes que se reuniam ao redor de suas memórias em ruínas, como em um réquiem.

Fizemos das noites nossos dias, de olhos semicerrados, nos voltamos ao horizonte e vimos. Bem lá no fundo, o dia amanhecia. (STÅLENHAG, 2015, p. 125, tradução nossa)

A passagem de tempo e as mudanças trazidas com ela são o foco desse fim. Ressaltamos ainda três elementos que serão cruciais para compreender o fenômeno de Contos do Loop e Ur Varselklotet e sua tensão com o imaginário distópico, um no plano social, um no plano tecnológico e um no plano subjetivo.

Seguindo uma estrutura recorrente ao longo do livro, o fragmento começa com um olhar mais panorâmico, social, do fenômeno. Em muitos dos outros textos, o primeiro parágrafo era dedicado à contextualização de datas de chegada de alguma empresa ou tecnologia, ou quando deixaram de existir. Nesse momento final, vemos, assim, a transição de uma visão da ciência como um patrimônio estatal para o mundo das grandes corporações tecnológicas - que imperarão nos mundos distópicos pós-modernos.

Depois, focando-nos na interação entre sujeito e tecnologia, vemos uma transição do mundo analógico para o mundo digital, em que as brincadeiras na rua são substituídas por computadores e todos passam o dia olhando telas brilhantes. Um dos fascínios de Ur Varselklotet é justamente com as máquinas em sua materialidade, em sua plasticidade, remetendo a um mundo em que elas é que se inseriam em nosso espaço e não 
nós que migrávamos para o ambiente virtual regido por elas novamente, ponto que caracterizará séries como Black Mirror.

Por último, uma transição de uma perspectiva infantil sobre o mundo a uma amadurecida, crítica, que não mais é capaz de um olhar ingênuo, curioso, quase místico para aquele mundo científico-tecnológico. Esse olhar é fundamental para construir um espaço idealizado, completamente alheio a aspectos que como veremos mais adiante - fizeram dos anos 80 e do começo dos 90 uma época de consolidação dessas mesmas angústias tecnológicas contemporâneas das quais Ur Varselklotet e Contos do Loop tentam se afastar. Tanto é assim, que o cyberpunk surge nessa época, no mesmo momento em que o retrofuturismo tentava projetar na era de ouro da ficção científica dos anos 30 e 40 os ideais que hoje deslocamos para os anos 80 e 90.

E se hoje temos Black Mirror, outro importante espelho sombrio refletia os anseios daquela época, Mirrorshades (1986), organizado por Bruce Sterling, um dos pontos inaugurais do cyberpunk, que nos servirá de ponto de partida para entender como o retrofuturismo reage à distopia como potência de esperança e renovação.

\section{OLHAR O PASSADO PARA ENXERGAR O FUTURO}

A introdução a The Routledge Companion to Cyberpunk Culture recupera um popular twitter enviado pelo escritor e game designer Kyle Marquis em 2013 que sintetiza bem certo sentimento que prevalece na contemporaneidade:

“A não ser que você tenha mais de 60 , você não recebeu promessas de carros voadores. Você recebeu promessas de uma opressiva distopia 
cyberpunk. Aqui está". No âmago da afirmação de Marquis está a conclusão de que a realidade de hoje não é ficção científica no sentido da Era de Ouro dos anos de 1940 e 1950, mas tal como é representada pelo cyberpunk, aquela vastamente popular forma de ficção científica dos anos 80 que continua a dialogar com nosso momento atual. (MCFARLANE et al, 2020, p. 1, tradução nossa)

Essa mudança na perspectiva de futuro que se consolida com o movimento cyberpunk - mas que já encontra antecedentes, por exemplo, na literatura de Phillip K. Dick e em algumas obras da ficção científica new wave nos anos 60 e 70 -, como percebido pelos autores, ainda parece predominar se levarmos em conta a popularidade da temática distópica - em sentido amplo na literatura, televisão e cinema contemporâneos. Marquis estabelece entre o nosso momento e o passado cyberpunk uma relação de causa e consequência: nós seríamos a concretização do futuro sombrio antevisto pelos escritores do gênero, o que ecoa o caso que já vimos da falsa propaganda de Black Mirror e a coluna de Daniel Olivas no The New York Times. Ainda que seja uma sedutora, e, sem dúvida, popular opinião, essa ideia de que, agora, vivemos uma distopia, já estava presente desde o início do movimento cyberpunk.

Em um dos livros que consolida o gênero na literatura, Mirrorshades (1986), Bruce Sterling escreve um prefácio em que tece comentários importantes sobre quem seriam esses autores cyberpunks e que tipo de abordagem traziam à ficção científica. Ainda no começo de seu texto, surge a afirmativa que remete ao twitter de Marquis: "Os cyberpunks são, talvez, a primeira 
geração da FC a crescer não apenas em uma tradição literária da ficção científica, mas em um mundo de ficção científica de fato" (STERLING, 1988, p. xi, tradução nossa).

Essa visão está ligada, sobretudo, a uma ubiquidade da tecnologia - seja ela mecânica, biológica, informática etc. - que começa a ser notada mais fortemente a partir dos anos 80 impulsionada pela terceira revolução industrial. Nas palavras de Sterling:

Os avanços das ciências são tão profundamente radicais, tão perturbadores, inquietantes e revolucionários, que eles não podem mais ser contidos. Eles estão se expandindo amplamente pela cultura; eles são invasivos; eles estão em todos os lugares. A tradicional estrutura de poder, as instituições tradicionais, elas perderam o controle sobre o ritmo das mudanças. (1988, p. xii, tradução nossa)

Uma chave, então, para entender a mudança causada no imaginário a partir do cyberpunk é essa brusca perda do controle diante da expansão cada vez mais rápida da tecnologia por todos os meios da sociedade. Vemos, também, Sterling associar às mudanças tecnológicas, outras de caráter social relacionadas à pósmodernidade. Segundo Sterling - influenciado pelo pensamento de Alvin Toffler em A terceira onda (1980) -, "[a] revolução técnica que está transformando nossa sociedade é baseada não em hierarquia, mas em descentralização, não em rigidez, mas em fluidez" (p. xii. Tradução nossa), antecedendo uma visão sobre as distopias pósmodernas que Bauman ratificará em conversa com Leonidas Donkis no livro Cegueira moral (2014).

É curioso notar, no entanto, que a noção de cyberpunk esboçada por Sterling não é sustentada sequer na sua própria 
coletânea, uma vez que alguns contos se afastam parcial ou mesmo completamente dessa vertente, como é o caso, por exemplo de "Tales of Houdini", de Rudy Rucker. Dentre esses contos menos representativos de uma visão mais restrita de cyberpunk, está um que é ocasionalmente utilizado para ilustrar outra vertente da ficção científica importante para nossa reflexão aqui, o retrofuturismo.

"The Gernsback Continuum", conto de William Gibson que abre Mirrorshades, narra a história de um fotógrafo que é contratado por um historiador de arte para capturar imagens das decadentes arquiteturas futuristas da Califórnia de décadas passadas. Demora um tempo para o que o próprio fotógrafo entenda o conceito: tentar representar um futuro que nunca chegou, uma década de 80 paralela, fruto das projeções ousadas de um passado que ainda mantinha fé na ciência e no progresso. Gibson sintetiza essa experiência na expressão: "Uma arquitetura de sonhos perdidos" (GIBSON, 1988, p. 5, tradução nossa).

O nome do título faz referência a Hugo Gernsback, criador da primeira revista dedicada plenamente à ficção científica, a Amazing Stories, até hoje símbolo do gênero. Com isso, Gibson aponta justamente para a visão de ciência que se busca recuperar nessa arqueologia de um futuro passado que contrasta com o presente sombrio dos 80 , o futuro dos foguetes, carros voadores e zepelins, mas também da esperança em uma utopia que não mais encontrava lugar no mundo pintado por Sterling em sua introdução.

O conto de Gibson em Mirrorshades serve aqui justamente para reforçar o ponto de que o mesmo contexto que possibilita o 
surgimento de uma vertente profundamente marcada por uma visão distópica de ciência e tecnologia também será responsável por outra cujas premissas, inicialmente, são quase opostas a do cyberpunk: o retrofuturismo. Nas palavras de Niklas Maak: "Retrofuturismo não é nada mais que uma estética de retorno cíclico, retomando uma crença perdida no progresso, as velhas imagens do que um dia foi radicalmente novo" (apud GUFFEY; LEMAY, 2014, p. 434, tradução nossa).

É curioso notar que, enquanto os abalos na visão da ciência acompanham todo o século $\mathrm{XX}$, como podemos notar pelo surgimento das distopias - das visões pioneiras de Wells a consolidação do gênero em Huxley e Orwell - é apenas no final do século, décadas após o terrível bombardeio de Hiroshima e Nagasaki, que encontraremos as condições que impossibilitam continuar projetando no futuro uma alternativa:

As expectativas futuristas despencaram pouco depois do começo da era espacial. Em meados dos anos 70, antecipações de um progresso sem fim, assim como as expectativas de que haveria infinitos recursos para alimentá-lo, entraram em declínio; além disso, muitos observadores começaram a questionar a inovação científica e refletir sobre o preço ecológico e social que ela demandava. A crise petrolífera, a recessão do meio aos finais dos anos 70 e os desastres ambientais como a poluição do Love Canal e Three Mile Island, tudo isso incitou questionamentos sobre os benefícios da tecnologia, sem sugerir soluções específicas. Mesmo que a NASA tenha levado a cabo seu programa Apollo, estava claro que os escritores pulp da FC haviam sido muito brandos na estimativa dos meios tecnológicos e financeiros necessários para colocar o homem no espaço. (GUFFEY; LEMAY, 2014, p. 436, tradução nossa) 
Condensado no texto de Guffey e Lemay, esse momento de crise pode ser visto de forma detalhada na Era dos extremos, de Hobsbawn (1995). O capítulo "As décadas de crise", mostra como o colapso da estabilidade econômica alcançada durante a chamada Era de Ouro levou a uma forte crise econômica e política. Parte dessa crise está diretamente relacionada com as próprias revoluções tecnológicas que deveriam nos trazer o progresso: o avanço na automatização torna dispensável cada vez mais uma parcela maior do proletariado; e o avanço na telecomunicação potencia a transnacionalização da produção, despovoando zonas industriais nos países de primeiro mundo e predando a mão de obra barata nos países em desenvolvimento. Com isso, a própria paisagem urbana dá sinais de decadência, com cinturões industriais abandonados à ferrugem e massas de semteto dormindo nas ruas, o que acabará por afetar o imaginário público da época.

Diante do centenário do manifesto futurista, em 2009, Franco Berardi (2009) desdobra, em Depois do futuro, essa situação sociopolítica no imaginário social, tanto no plano histórico quanto estético, tomando como ponto de partida simbólico o ano de 1977. O marco parte da letra de "God Save the Queen", do Sex Pistols, lançado naquele ano, declarando, em espírito semelhante ao de Marquis e Olivas, que "não há futuro". A partir dessa premissa, Berardi analisa a substituição de uma visão futurista em última instância otimista para o que ele chamará de um "iluminismo obscuro" - e que poderia ser traduzido por visão distópica -, ou seja, a crença de que o futuro representa uma ameaça ao programa humanista de mundo. 
É ainda no ano de 1977, ressalta Berardi, que Lyotard escreve $A$ condição pós-moderna, obra que nos ajuda a entender como essa visão acompanha uma mudança drástica na própria relação com a ciência. Para Lyotard, a condição pós-moderna é caracterizada pela descrença das metanarrativas, "o declínio do poder unificador e legitimador dos grandes relatos" (2009, p. 69), dentre os quais se incluem aqueles que legitimavam as visões modernas de ciência. Diante desse declínio, a ciência perde o relato que Ihe garantia sua teleologia, abalando também, dessa forma, as visões de futuro que abrigariam os progressos trazidos pela inovação científica.

O que ganha forma, assim, nos anos 80 não é apenas um desencanto ou uma desconfiança com a ciência - o que já se encontra em gerações anteriores da ficção científica, mesmo no século XIX -, mas uma paradoxal visão do futuro: por um lado, a ideia de que a tecnologia e o progresso sonhados pelas gerações anteriores haviam se tornado uma realidade cotidiana; por outro, que, essa concretização não trouxe consigo as promessas que as visões de futuro passadas nos apresentavam. Marcada por crises econômicas, políticas, ecológicas e mesmo epistemológicas, a esperança de que a crise do presente vai ser resolvida com o progresso é substituída pelo medo de que esse processo torne nossa realidade ainda mais precária.

Dessa visão paradoxal surgem duas formas igualmente conflitantes de lidar com as ansiedades resultantes dela: por um lado, através de uma crítica niilista do presente num futuro diferenciado apenas pelo traço do excesso - mais neon, mais implantes, mais computadores, mais corrupção, mais violência e 
mais desastres ambientais; por outro, através de uma projeção, algo irônica, das visões de progresso no único lugar que lhes restou, o passado.

É importante reforçar, no entanto, que esse retorno ao passado não coincide com uma recuperação verossímil de uma situação histórica, mas como um olhar nostálgico, idealizado e estetizado de uma era. Como já mencionamos, ao longo de todo o século $X X$, as distopias vinham criticando o papel da ciência na sociedade e os mesmos anos 30 vistos de forma nostálgica pelo retrofuturismo eram encarados de maneira bem distinta ao olharmos para Admirável mundo novo (1932), de Aldous Huxley, por exemplo.

O retrofuturismo procura, segundo Guffey e Lemay (2014, p. 434), assim, a transformação do futuro em um estilo, altamente marcado pela nostalgia, mas também por uma visão irônica e crítica do presente, que se ressalta justamente pelo contraste entre o imaginário futurista de ambas as eras. Muito voltadas ao surgimento do retrofuturismo nos anos 80 , em que o contraste com a era Gernsback marca bem a ideia de um retorno nostálgico, as autoras, no entanto, não parecem lidar com um problema contemporâneo do retrofuturismo: o fato de que nosso passado, hoje, é justamente aquele presente sem futuro que precisou olhar para trás, os anos 80 .

Se levarmos em conta que o surgimento do retrofuturismo se dá pelo estreitamento da possibilidade de imaginar um futuro em que o progresso científico leve a uma mudança significativa na sociedade, é quase paradoxal que as visões de futuro que tentamos, hoje, recuperar, apontem justamente para esse 
momento que foi marcado pelo começo da ausência dessa própria visão de progresso. Usando a definição proposta de que o retrofuturismo recupera uma visão de futuro do passado, encontraríamos frustrada a tentativa de um retrofuturismo positivo que apontasse para os anos 80/90, como Contos do Loop.

O problema se complexifica se levarmos em conta que essa separação entre progresso e decadência que poderia dividir o retrofuturismo do cyberpunk nos anos 80 muda de cenário na contemporaneidade, em que o cyberpunk se tornou, ao mesmo tempo, um estética de futuro datada e uma visão ainda válida de sociedade futura. Dessa forma, encontramos, duas formas diferentes de encarar o retrofuturismo: uma que aponta para uma visão perdida de futuro, altamente marcada pela nostalgia, e, assim, mais próximo ao retrofuturismo dos 80 - como, defendemos, é o caso da criação de Stålenhag - e outra, mais recente, tão distópica quanto as visões contemporâneas, mas marcadas por uma estética e tecnologias ultrapassadas ${ }^{4}$ - como, por exemplo, Blade Runner 2049 (2017), de Dennis Villeneuve.

Enquanto o retrofuturismo mais distópico seria, talvez, mais preciso em relação às visões predominantes de ciência e sociedade nos anos 80/90, o retrofuturismo mais otimista se alinha melhor às propostas do gênero levantadas por Guffey e Lemay. No entanto, para superar o paradoxo anteriormente apontado nas obras que projetam um futuro num passado sem futuro, é preciso reforçar a ideia de que essa projeção é menos uma recuperação factual de um

4 Para alguns autores, como Joe P. L. Davidson (2019, p. 730), o retrofuturismo não é simplesmente a exploração das visões de futuro do passado, mas de um passado específico: o tecnofilismo futurista americano - e em menor medida europeu encontrado entre os anos de 30 e 60 do séc. XX. 
contexto científico que uma construção idealizada em um passado reformulado pela nostalgia.

Esse retorno idealizado permite, então, uma seleção e isolamento de aspectos que apontem para a visão de futuro que, na verdade, a obra mais cria do que recupera. Nesse processo, mesmo elementos que outrora foram símbolos importantes do cyberpunk podem ressurgir como índices nostálgicos de um tempo mais simples: o computador pessoal, antes símbolo da invasão tecnológica, é agora uma agradável lembrança de um tempo em que os celulares não controlavam nossa rotina; as placas em neon, mais distintivo traço estético do cyberpunk, se transforma, agora, em uma lembrança de um tempo anterior aos pop-ups e sugestões de propaganda baseado em algoritmos; a própria integração das máquinas no dia a dia conforta como aspecto palpável da tecnologia diante de um mundo angustiado com a crescente virtualização das atividades.

Como bem apontam Guffey e Lemay (2014, p. 444), esse processo de manipulação das visões de passado e futuro está associado a posicionamentos políticos específicos. Em alguns casos, isso pode levar a impulsos conservadores como os que hoje inclinam diversos países ao totalitarismo fascista do século XX - sobre o tema, vale uma leitura de Retrotopia (2017), de Zygmunt Bauman. Em outros, no entanto, surgem como impulso de esperança, como propõe Joe L. P. Davidson:

Eu sugiro que o retrofuturismo tem uma função de esperança. Isso é, através da recuperação e exposição de sonhos não realizados do passado é possível renovar o impulso utópico, recuperando 
- poder residual das velhas imagens do novo para reformular nosso entendimento do futuro. (DAVIDSON, 2019, p. 731, tradução nossa)

Acreditamos, assim, alinhados ao pensamento de Davidson, que Ur Varselklotet funciona, então, como processo de resistência a uma visão predominantemente distópica de futuro que pudemos ver nos casos mencionados ao longo deste artigo. Se essa tensão se torna clara na irrupção quase simultânea entre o cyberpunk e o retrofuturismo, ela acompanha um contexto social para além dos limites literários ao que vale dedicar algumas considerações.

Não é preciso pesquisar muito para encontrar, na internet, vídeos de bebês que, antes de dominar a fala, já são capazes de operar com precisão um tablet ou celular através do touchscreen. Essa geração de nativos digitais, da qual os primeiros exemplares já não são bebês há um tempo, transmite, a princípio, a ideia de uma relação íntima com a tecnologia. No entanto, esse contato se dá majoritariamente, e cada vez mais, não com os processos envolvidos em sua produção, mas unicamente com o produto final. $\mathrm{O}$ abismo crescente entre as potências da tecnologia contemporânea e a alienação do sujeito de seus meios de produção ${ }^{5}$ gera uma também crescente ansiedade perante seus efeitos sobre o mundo.

Se a ficção científica pode, por um lado, auxiliar na familiarização de certos conceitos científicos ou tecnologias, diminuindo, assim, a desconfiança em relação à sua circulação na sociedade, não é raro tampouco que suas obras adquiram uma função admonitória, buscando alertar sobre os perigos que o mau uso desses avanços

5 Abismo cujo pináculo, supomos, se dê no uso de algoritmos de inteligência artificial atualmente, em que, mesmo os próprios programadores só dominam a superfície dos processos autoaprendidos pelo sistema. 
pode trazer à humanidade. Com isso, dão voz às ansiedades já presentes em germe na sociedade, magnificando o medo produzido por esses elementos que fogem ao controle ou ao conhecimento da população geral.

Ainda que tal função já se encontre presente nos primeiros passos da ficção científica, em que Mary Shelley ou Robert Louis Stevenson apontam os perigos de se extrapolar certos limites na ciência, é, sobretudo, a partir das últimas décadas do século XX que, como veremos, a balança começa a pender majoritariamente para o lado dos horrores que podem ser trazidos pelo futuro.

Guffey e Lemay (2018, p. 435) separam o futurismo em três fases que podemos usar aqui como guias para pautar a formação desse imaginário social sobre a ciência: (i) uma primeira fase ancorada no otimismo oitocentista, que via no progresso tecnológico um claro caminho à utopia social ${ }^{6}$; (ii) outra fase do começo do séc. XX até os anos 60, fortemente embalada pela exploração espacial; (iii) e uma terceira, de declínio e perda da empolgação futurista, que começa em meados dos anos 60 e se consolida nos 70 .

As revoluções sociais e tecnológicas que começam a ganhar forma no séc. XVIII e se consolidam no XIX não vão ser importantes apenas para a instauração de um futurismo utópico, mas para a própria noção de futuro e de progresso ${ }^{7}$. Da revolução industrial à luz elétrica, de Darwin a Pasteur, do iluminismo ao positivismo, a ciência operou mudanças na sociedade em uma velocidade nunca

6 Reforçamos novamente que tais visões ainda eram contrabalançeadas com perspectivas mais críticas a essa progresso, como vemos em Charles Dickens, H. G. Wells ou Jack London.

7 Para uma discussão mais detida sobre a fundação da ideia de futuro e progresso, cf. Kosseleck, 2006. 
antes imaginada, servindo de combustível para o surgimento de uma ficção entusiasmada com a ciência e com seus prognósticos para o futuro.

Apesar da fumaça e da exploração cruel do proletariado, o otimismo avança pelo começo do séc. $X X$ e só sentirá o seu primeiro forte abalo diante da Primeira Guerra Mundial, com seus aviões de combate e gás-mostarda, abalo este que servirá de evento inaugural para um amplo leque de atrocidades que a ciência vai se mostrar capaz ao longo do século, até consolidar o medo da própria aniquilação da Terra no auge da guerra fria. É nessa século que vemos o gênero da ficção distópica se firmar, com obras como Nós (1924), de Yevgeny Zamyatin, Admirável mundo novo (1932), de Aldous Huxley, e 1984 (1949), de George Orwell, mostrando todo o potencial sombrio dessas grandes revoluções sociocientíficas.

Notemos, no entanto, que esse momento coincide justamente com a era de ouro do futurismo e não com seu alvorecer. É importante frisar que mesmo essas obras distópicas, que veem um futuro aterrorizante através dessa tecnologia ascendente, não deixam de demonstrar uma confiança inabalável no progresso tecnológico: um pouco menos explorado em 1984, mas claramente visível em Nós, Admirável mundo novo, ou, ainda, Fahrenheit 451 (1953), de Ray Bradbury.

O mais surpreendente das visões da ciência ao longo do século XX é essa paradoxal reação do mundo perante a tecnologia: resiste uma ideia de progresso apesar da destruição que ele traz consigo. Por um lado, essa ideia é respaldada por uma antagonização de 
outras nações que justificava um uso destrutivo da tecnologia como forma de proteção; e por outro, é direcionada para projetos científicos ainda capazes de mobilizar o imaginário humano de forma positiva, dentre os quais vale destacar a corrida espacial, um dos maiores combustíveis da ficção científica da dita era de ouro do gênero.

Se mesmo diante dos horrores absolutos de Hiroshima e Nagazaki ainda foi possível manter essa noção de progresso, o que faz com que o final dos anos 60 e, sobretudo, os 70, representem uma decadência das visões de futuro que culminará no cyberpunk dos 80 ?

Guffey e Lemay apontam para um conjunto de crises que ajudam nesse declínio: a crise energética, a crise ecológica e a crise econômica, todas indicando a incapacidade de dar continuidade ao projeto de progresso infinito aventado no século anterior: a sociedade não o conseguia bancar, o meio ambiente ameaçava entrar em colapso e o sonho das estrelas se mostrou bem menos otimista que a princípio se fazia crer. Com isso, o espaço para especulações de futuros drasticamente diferentes se estreita, dando lugar a visões em que a ciência e tecnologia apesar de prodigiosas são incapazes de gerar grandes mudanças sociais, ofuscando as sociedades imaginadas do futurismo - mesmo o futurismo distópico tradicional, que vai dando lugar às distopias pós-modernas, em que as sociedades retratadas não são muito distintas da nossa (CLAEYS, 2017, p. 477).

Vale, ainda, destacar como há uma progressiva mudança de perspectiva sobre a própria lógica interna de evolução da ciência 
que colaborará para distanciar o público de suas atualizações, reforçando a ideia de estagnação: o abandono da intuitividade nas teorias científicas (ASSIS, 1996), que emerge ainda no final do século XIX, mas demora décadas a começar impactar o imaginário social. Um sinal disso é o próprio abandono da metáfora de mundo-máquina, onde os fenômenos naturais poderiam ser entendidos como engrenagens de um relógio, partes que faziam funcionar o todo. Cada uma dessas partes poderia ser analisada individualmente, tornando a compreensão do todo mais possível e intuitiva. Com a ascensão de concepções contra intuitivas, como na teoria da Relatividade e na Quântica - além da própria informática -, a população leiga foi ficando cada vez mais distante da ciência.

Esse distanciamento na compreensão do funcionamento dos fenômenos e da própria tecnologia que se agrava ao longo do séc. XX vai levar a uma inversão definitiva na representação das relações humano-máquina, na qual os homens deixam de ter o protagonismo e controle sobre as máquinas para se tornarem vigiados, controlados e, em última instância, reificados pela própria tecnologia - um dos principais temas tanto para o cyberpunk, quanto para Black Mirror e seus semelhantes.

O próprio ensino tradicional das ciências nas escolas parece não dar conta de alterar essa perspectiva. Aborda-se, ainda, a ciência como uma instituição neutra, que trata de forma objetiva os fatos, assume verdades como absolutas e não admite incertezas inerentes ao fazer humano - Em especial no cenário brasileiro, essa ciência indutivista e dogmática carrega valores herdados ainda dos manuais de escolas politécnicas francesas que serviram de base para o ensino no país (BRAGA; GUERRA; REIS, 2008). 
Essa neutralidade vem sendo problematizada há décadas por pesquisadores - como (MATTHEWS, 1995; REIS; GUERRA; BRAGA, 2006) que afirmam que a solução não seria colocar a ciência novamente num pedestal, retornando a uma visão idealizada de pureza absoluta. Eles apontam a necessidade de uma reaproximação das ciências exatas e da natureza com as ciências humanas para ampliar esse imaginário sobre o que realmente é a prática científica. Boaventura de Souza Santos (2006) aponta que essa reaproximação seria um dos pilares de um paradigma emergente para as ciências, com essa convergência de saberes que construiria visões mais complexas da praxis científica e humanizaria seus agentes.

E é no impulso dessa procura por alternativas que, acreditamos, Ur Varselklotet e Contos do Loop surgem como exemplares de uma ficção capaz de reforçar um paradigma diferente de ciência. Por um lado, o deslocamento para o passado é uma forma de, em algum grau, recuperar a relação intuitiva mundo-máquina, o que vemos bem representado pela integração quase orgânica que Stålenhag cria em suas pinturas. Ainda que o Loop seja uma instalação de pesquisa justamente desses saberes que se afastam do caráter intuitivo da ciência - como a quântica -, a visão infantil substitui a abstração técnica pela curiosidade: é explorando as ruínas e sucatas que se dá a integração homem-máquina, humanizando o contato com a ciência.

É, ainda, através desse olhar ao passado que se busca um afastamento de uma visão consolidada pelo cyberpunk e magnificada pelas distopias contemporâneas: a indissociabilidade entre ciência e interesses capitalistas, representado normalmente pelas gigantes multinacionais da indústria tecnológica. Ao 
representar a pesquisa científica como um meio para a obtenção de um produto vendável, essas vertentes criticam o utilitarismo absoluto que toma hoje as visões de ciência propagada pelo neoliberalismo. Já o retrofuturismo de Stålenhag ${ }^{8}$, seguindo a mesma crítica, oferecerá um retorno a um passado de investimento estatal em pesquisa, que libera a ciência de uma instrumentalização e permite uma recuperação do seu potencial criativo e explorador. Na série vemos, por exemplo, como o centro alcança criar androides com inteligência artificial, que no livro são apenas sugeridos. No entanto, seu único uso naquele espaço retroutópico é comunitário: transformado em professor, o robô é responsável pela educação de diversas gerações de alunos da cidade.

Mais do que simplesmente um impulso de esperança, esse tipo de representação colabora para consolidar no imaginário uma visão positiva de tais centros de pesquisa. Vale lembrar que notícias sobre o LHC - o Grande Colisor de Hádrons, cuja estrutura física parece inspirar a própria concepção do Loop -, nos meses que precederam sua ativação em 2008, revelavam diversas preocupações do público leigo tanto com acidentes quanto com a validade do dos vastos recursos investidos nele. Uma das teorias da conspiração famosas à época afirmava que as colisões entre partículas realizadas no acelerador poderiam gerar um buraco negro que engoliria o planeta Terra. Hoje a Organização Europeia

8 A série, fazendo a transposição para a lógica americana, não deixa tão claro o caráter governamental do centro de pesquisas. Há, também, uma precarização dos trabalhos de manutenção, feitos provavelmente por uma empresa terceirizada, que não aparece da mesma forma em Ur Varselklotet. Ainda assim, não vemos usos comerciais da tecnologia, mantendo funcional, ainda o impulso de uma representação positiva da pesquisa científica. 
de Pesquisa Nuclear, CERN, trabalha ativamente com divulgação de seus projetos para o público leigo.

O Brasil também mantém seu próprio Loop: o Sirius, acelerador de partículas que opera no Laboratório Nacional de Luz Síncrotron (LNLS) em Campinas, SP. O acelerador possibilita experimentos das mais diversas áreas e trabalha constantemente com pesquisadores externos e com a indústria para produzir aplicações tecnológicas. Uma das últimas conquistas do laboratório foi a produção das primeiras imagens 3D de proteínas do coronavírus, que funcionariam como mapas para otimizar futuros medicamentos. A grande preocupação com a divulgação científica se traduz em eventos como o Ciência Aberta, que todos os anos abre as portas para milhares de visitantes leigos. Um empreendimento dessa escala precisa garantir uma boa imagem, não podendo mais se eximir de defender sua relevância social e garantir investimentos sejam eles públicos ou privados.

Se a obra de Stålenhag precisa olhar para o passado para projetar esses ideais, o faz não apenas por nostalgia, mas por uma esperança de que é possível moldar um futuro que escape das predições sombrias dos muitos Black Mirrors que o rodeiam. Recuperando não um contexto real do passado - que, como vimos, nos anos 90 não estava muito melhor do que hoje - mas certo ideal remodelado pela nostalgia, o retrofuturismo é a paradoxal prova de que é possível ver futuros melhores, futuros esses que continuam sendo buscado por certas iniciativas que hoje apenas perdem espaço no imaginário para visões mais negativas da ciência e do progresso. 


\section{CONSIDERAÇÕES FINAIS}

A crítica russa Svetlana Boym, em The Future of Nostalgia, nos ajuda a entender a tensão entre a distopia e o retrofuturismo que viemos discutindo ao longo deste artigo:

Um ditado russo contemporâneo diz que o passado se tornou mais imprevisível que 0 futuro. A nostalgia depende dessa estranha imprevisibilidade. De fato, nostálgicos de todo mundo encontrariam dificuldade em dizer o que exatamente pelo que eles anseiam. Um outro lugar, outra época, uma vida melhor. O fascinante objeto da nostalgia é claramente elusivo. O ambivalente sentimento permeia a cultura popular do século $X X$, em que avanços tecnológicos e efeitos especiais são frequentemente usados para recriar visões do passado, do Titanic naufragando aos gladiadores morrendo e os extintos dinossauros. De alguma forma o progresso não curou a nostalgia, mas a exacerbou. De forma semelhante, a globalização encorajou vínculos locais mais fortes. Em contrapartida à nossa fascinação com o ciberespaço e a aldeia virtual global, há uma não menor epidemia de nostalgia, um anseio afetivo por uma comunidade com memória coletiva, um desejo por continuidade em um mundo fragmentado. Nostalgia inevitavelmente reaparece como um mecanismo defensivo em um momento de ritmo acelerado de vida e convulsão histórica. (2001, p. 13, tradução nossa)

Nos anos 80, a revolução informacional, ao lado das crises, criaram esse coquetel de "ritmo acelerado de vida e convulsão histórica" necessário para dar vida tanto a uma visão distópica de futuro, o cyberpunk, quanto um impulso nostálgico em busca de 
estabilidade, o retrofuturismo. Hoje parecemos estar diante de um novo pico nas mudanças sociais. A crise da democracia e a ascensão dos novos regimes de inclinação fascista, a crise da legitimidade da informação, os escândalos de manipulação de usuários pelos algoritmos das redes sociais, o crescente negacionismo e o agravamento da crise ecológica apontam para um momento em que a esse impulso nostálgico se faz mais presente do que nunca, não só na ficção científica, mas, como recentes estudos vem mostrando (BOYM, 2001; BAUMAN, 2017), na sociedade de forma geral.

Se, por um lado, essa tensão indica uma reviravolta na função do futuro e do progresso, que deixam de ser o depósito das esperanças do homem para se tornar o espaço de seus pesadelos (BAUMAN, 2017, p. 6) - culminando na prolífica produção da ficção distópica contemporânea -, o mesmo movimento desloca esse potencial de esperança para o passado. E, se é certo que reside nesse apelo nostálgico uma vulnerabilidade a discursos ufanistas e fascistas (BOYM, 2001, p. 41), também é certo que essa retrotopia pode assumir função análoga a do gênero que lhe empresta o sufixo: a de combater o pesadelo futuro através da imaginação de mundos melhores, não menos possíveis por se situarem num passado, uma vez que tal passado, drasticamente alterado pela idealização nostálgica, se esvazia de um sentido histórico para se tornar um signo de resistência ao futuro distópico que se delineia no horizonte.

\section{REFERÊNCIAS}

ASSIS, Jesus de Paula. Visões do futuro: imagens da ciência e do cientista. Lua Nova, São Paulo, n. 37, p. 209-228, 1996.

BAUMAN, Zygmunt. Retrotopia. Cambridge: Polity Press, 2017. 
BAUMAN, Zygmunt; DONSKIS, Leonidas. Cegueira moral. Rio de Janeiro: Zahar, 2014.

BERARDI, Franco. Depois do futuro. Tradução de Regina Silva. São Paulo: Ubu, 2019. BRAGA, Marco; GUERRA, Andreia; REIS, José Claudio. O papel dos livros didáticos franceses do século XIX na construção de uma concepção dogmáticoinstrumental do ensino de física. Caderno Brasileiro de Ensino de Física, [S. I.], v. 25, n. 3, p. 507-522, dez., 2008.

BOYM, Svetlana. The Future of Nostalgia. Nova lorque: Basic Books, 2001.

CAIN, Sian. Distopia with hot chocolate: Tales from the Loop's author on his low-key sci fi. The Guardian, International edition, 14 Apr., 2020. Available at: https://www.theguardian.com/books/2020/apr/14/tales-from-the-loopauthor-simon-stalenhag. Accessed on: $28^{\text {th }}$ Sept. 2020.

CLAEYS, Gregory. Dystopia: a Natural History. Oxford: Oxford University Press, 2017.

DAVIDSON, Joe L. P. Blast from the past: hopeful retrofuturism in science fiction film. Continuum, v. 33, n. 6, p. 729-743, 2019.

GUFFEY, Elisabeth; LEMAY, Kate C. Retrofuturism and Steampunk. In: LATHAM, Rob. The Oxford Handbook of Science Fiction. Oxford: Oxford University Press, 2014. GUY, Lodge. The best 10 Dystopias. The Guardian, International edition, 8 Aug. 2014. Available at: https://www.theguardian.com/culture/2014/aug/08/the10-best-dystopias. Accessed on: 29 ${ }^{\text {th }}$ Sept. 2020.

HOBSBAWN, Eric. Era dos extremos: o breve século XX (1914-1991). São Paulo: Companhia das Letras, 1995.

KOSELLECK, Reinhart. Espaço de experiência e horizonte de expectativa: duas categorias históricas. In. KOSELLECK, Reinhart. Futuro Passado: contribuição à semântica dos tempos históricos. Tradução de Wilma Patrícia Maas e Carlos Almeida Pereira. Rio de Janeiro: Contraponto/Ed. PUC-Rio, 2006.

LYOTARD, Jean-François. A condição pós-moderna. Tradução de Ricardo Côrrea Barbosa. 12. ed. Rio de Janeiro: José Olympio, 2009.

MATTHEWS, Michael R. História, filosofia e ensino de ciências: a tendência atual de reaproximação. Caderno Catarinense de Ensino de Física, [S.I.], v. 3, n. 12, p. 164-214, dez., 1995. 
OLIVAS, Daniel A. The Dystopia Is Here. The New York Times, 19 June, 2018. Available at: https://www.nytimes.com/2018/06/19/opinion/childrenseparated-from-parents-border-immigrant-dystopia.html. Accessed on: $26^{\text {th }}$ Sept. 2020.

REIS, José Claudio; GUERRA, Andreia; BRAGA, Marco. Ciência e arte: relações improváveis. História, Ciências, Saúde - Manguinhos, v. 13, p. 71-87, 2006.

SANTOS, Boaventura de Souza. Um discurso sobre as ciências. 5. ed. São Paulo: Cortez, 2008.

STÅLENHAG, Simon. Tales from the Loop. Los Angeles: Design Studio Press, 2015. STERLING, Bruce. Mirrorshades. Nova lorque: Ace Books, 1988. 